\title{
Large Inverted Colonic Diverticulum (LICD)
}

\section{Hormati $\mathrm{A}^{1 *}$, Ghadir $\mathrm{MR}^{1}$, Sarkeshikian $\mathrm{SS}^{1}$, Iranikhah $\mathrm{A}^{2}$ and Yousefi $\mathrm{MH}^{3}$}

${ }^{1}$ Assistant Professor of Gastroenterology, Gastroenterology \& Hepatology Research Center, Qom University of Medical Sciences, Iran

${ }^{2}$ Assistant Professor of Pediatric Gastroenterology, Gastroenterology \& Hepatology Research Center, Qom University of Medical Sciences, Iran ${ }^{3}$ Research and bio-statistics expert, Gastroenterology \& Hepatology Research Center, Qom University of Medical Sciences, Iran

Received: 睯 March 15, 2018; Published: 些 May 21, 2018

*Corresponding author: Ahmad Hormati, Gastroenterology \& Hepatology Research Center, Shahid Beheshti Hospital, Qom School of Med, Qom University of Medical Sciences, Iran

\section{Case Report}

A 61 years old woman was referred to gastroenterology clinic for evaluation of abdominal pain. She complained from changeless pain in RUQ persisting for three months. She didn't have any other symptoms, anemia, and weight loss.
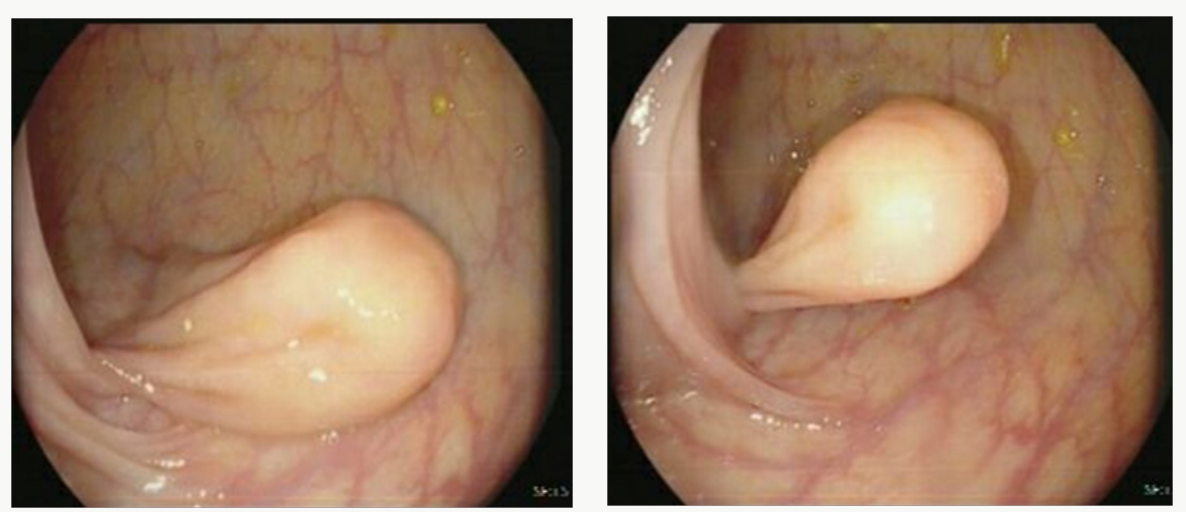

Figure 1\&2: Endoscopic view of $30 \times 15 \mathrm{~mm}$ lesion in the ascending colon.

In physical examination, patient didn't have any abnormal sign. Laboratory test were normal. Colonoscopy of the patient showed a $30 \times 15 \mathrm{~mm}$ sub mucosal lesion in the Ascending colon near to hepatic flexure. In gross view the sub mucosal lesion was similar to normal mucosa with large circumferential pedicle that changed its appearance according to low and high insufflations degree (Figure $1 \& 2)$.
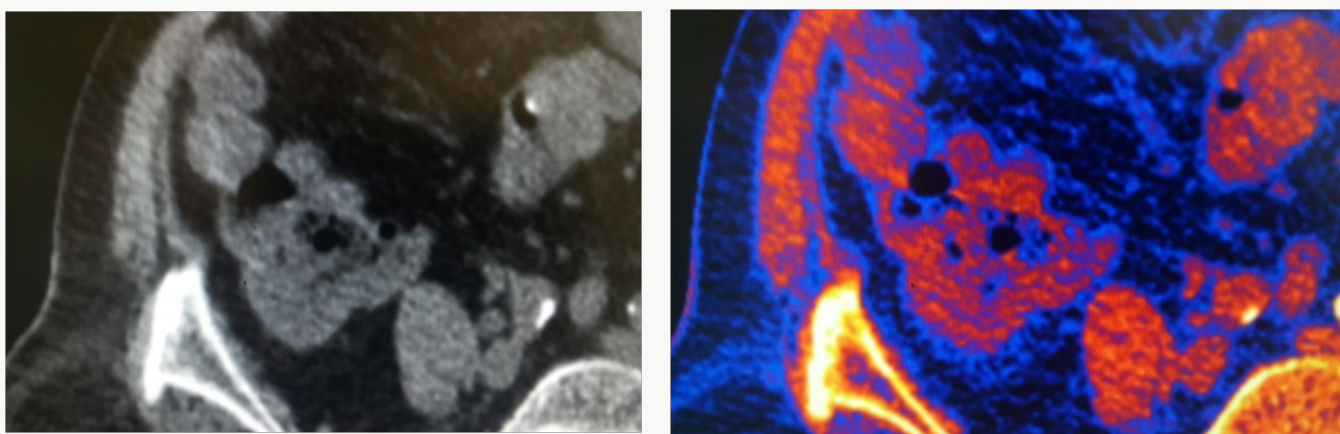

Figure 3\&4: Well-margined intraluminal mass like lesion measured $31 \times 16 \mathrm{~mm}$ contain some small gas bubbles is noticed (on Computed Tomography). 
CT scan revealed a well-margined intraluminal mass in proximal portion of the Ascending colon measured $31 \times 16 \mathrm{~mm}$ containing some small gas bubbles with suggestion of a large inverted colonic diverticulum (ICD) (Figure 3-5).

True colonic polyps and Gastrointestinal Stromal Tumors (GISTs) are main differential diagnosis for ICD. This differentiation is very important during colonoscopy. Polypectomy is contraindicated in ICD because of the risk of colonic perforation [1].

ICD occurred in $0.7 \%$ of population. Some maneuvers such as air insufflations [2,3], attempting to revert of the lesion with forceps [4], or water jet deformation sign [1] help colonoscopists in diagnosis of ICD.

\section{Reference}

1. Cappell MS (2009) The water jet deformation sign: a novel provocative colonoscopic maneuver to help diagnose an inverted colonic diverticulum. South med J 102(3): 295-298.

2. Adioui T, Seddik H (2014) Inverted colonic diverticulum. Ann Gastroenterol 27(4): 411.

3. Yusuf SI, Grant C (2000) Inverted colonic diverticulum: a rare finding in a common condition? Gastrointest Endosc 52(1): 111-115.

4. Triadafilopoulos G (1999) Inverted colonic diverticulum. New England Journal of Medicine 341(20): 1508.

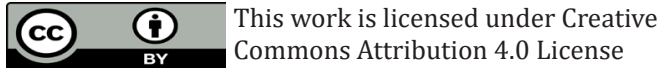

To Submit Your Article Click Here:

Submit Article

DOI: 10.32474/LOJNHC.2018.01.000109

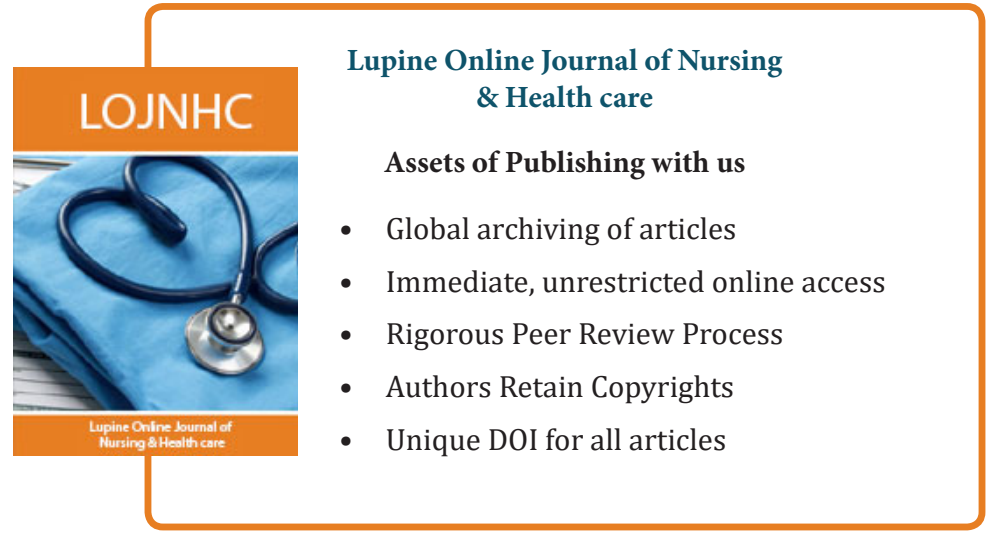

